\title{
Síndrome de Clérambault: desafio diagnóstico e terapêutico
}

\author{
De Clérambault's syndrome: diagnostic and therapeutic challenge
}

\author{
Thais de Moraes Sampaio ${ }^{1}$, Arthur Guerra de Andrade², Danilo Antônio Baltieri ${ }^{3}$ \\ ${ }^{1}$ Médica residente de Psiquiatria, Faculdade de Medicina do ABC, Santo André, SP. ${ }^{2}$ Professor titular, Disciplina de Psiquiatria e Psicologia Médica, \\ Faculdade de Medicina do ABC. ${ }^{3}$ Coordenador, Programa de Residência Médica de Psiquiatria, Faculdade de Medicina do ABC.
}

\section{Resumo}

A síndrome de Clérambault, ou erotomania, é descrita como uma convicção delirante, apresentada, geralmente, por uma mulher que acredita que um homem, mais velho e de posição social mais elevada, ama-a. O paciente persegue o objeto de amor e, por isso, eventualmente, envolve-se em retaliações e ameaças em resposta às repetidas rejeições. Relata-se o caso de uma mulher de 42 anos que iniciou quadro delirante há 19 anos, após primeira gestação. Foi admitida em nosso serviço há 3 meses. No início do tratamento, quando o antipsicótico foi introduzido, apresentou remissão do delírio. Essa síndrome é incomum, mas não significa que seja rara em nossa prática. Um bom entendimento da extensão psicopatológica pode aumentar o reconhecimento dessa condição psiquiátrica.

Descritores: Erotomania, síndrome de Clérambault, psicose, delírio.

\begin{abstract}
De Clérambault's syndrome or erotomania is described as a delusional conviction, in which a woman usually believes that an older man of higher social status is passionately in love with her. The patient's relentless pursuit of the delusional love object can eventually involve threats or retaliation, in response to repeated rejection. This case report is about a 42-year-old female who initiated the delusional conviction 19 years ago, after her first pregnancy. She was admitted to our service 3 months ago. In the beginning of the treatment, when the antipsychotic was introduced the patient exhibited decreasing of delusions. This disorder is uncommon but it does not mean that it is rare in our practice. A greater awareness of psychopathological extension may increase the recognition of this psychiatric condition.
\end{abstract}

Keywords: Erotomania, Clérambault's syndrome, psychosis, delusion.

\section{Introdução}

Relatos dos séculos 17 e 18 descreveram as chamadas "variantes" do amor patológico, tais como a ninfomania (furor uterinus), a erotomania (amor insanus) e a melancolia erótica. Durante toda a história, existiram muitas discordâncias entre diversos autores, médicos ou não, a respeito dos comportamentos de alguns apaixonados ou amantes. Freqüentemente, os termos paixão e loucura eram usados simultaneamente e com os significados mais diversos ${ }^{1,2}$.
No século 19, Emil Kraepelin, em seu monumental Maniac-Depressive Insanity and Paranoia, discutiu os limites entre dementia praecox (esquizofrenia), insanidade maníaco-depressiva e paranóia. Nessa última entidade, a erotomania foi considerada um subtipo. Kraepelin, então, definiu paranóia como um delírio indestrutível, de início insidioso, resultado de causas internas, acompanhado da preservação total da forma e do curso de pensamento ${ }^{3}$.

Apesar da definição de erotomania como uma forma de paranóia proposta por Kraepelin, ela foi 
eternizada com o nome de síndrome de Clérambault, após a publicação da eminente obra Les Delires Passionels. Gaëtan Gatian de Clérambault, em 1921, descreveu uma condição mental em que há convicção delirante, na qual um indivíduo, no geral uma mulher, acredita que é amada por alguém comumente de posição social e financeira proeminente. O doente tende a insistir que o objeto de amor é quem se apaixona primeiro e é ele quem faz as primeiras investidas amorosas, ou seja, é o objeto quem declara o interesse sexual inicial ${ }^{4}$.

O indivíduo costuma descrever detalhadamente as evidências do amor correspondido, através de mensagens por meio de olhares, comunicação verbal ou não-verbal, gestos ou até mesmo através de telepatia, exercidos intencionalmente pelo objeto ${ }^{5,6}$.

A erotomania costuma persistir, apesar dos esforços por parte do objeto amado em negar tal interesse. Essa negação pode ser interpretada paradoxalmente pelo paciente como um "disfarce" da declaração de amor ${ }^{2,7}$.

A incidência da erotomania não é bem definida. Há relatos que mostram que pode acometer $0,3 \%$ da população. São consideradas entidades raras, pouco descritas na literatura ${ }^{2}$.

De acordo com Mullen \& Pathé, as patologias do amor ocorrem em mulheres e homens, homo ou heterossexuais, em culturas orientais e ocidentais. É variável no que se refere a idade, raça e estado socioeconômico ${ }^{2,8}$.

Os pacientes do sexo feminino predominam nas amostras clínicas gerais; porém, em amostras forenses, a maioria é do sexo masculino ${ }^{2,9}$.

Não é possível afirmar a influência da hereditariedade nessa síndrome devido aos poucos casos descritos, apesar de alguns estudos relatarem a ocorrência desse transtorno na mesma família ${ }^{10}$.

Alguns autores classificam a erotomania de diferentes formas. Ellis \& Mellsop, por exemplo, classificam-na em primária e secundária. A primeira é rara, não é associada a nenhum outro transtorno psiquiátrico, apresenta início súbito e baixa resposta ao tratamento medicamentoso ${ }^{11}$. A outra forma, que corresponde à maioria dos casos, tem início insidioso e ocorre secundariamente a outras desordens psiquiátricas $^{12,13}$.

Na literatura médica brasileira, a ocorrência da erotomania é ainda menos divulgada. Além disso, parece ser subdiagnosticada, o que contribui ainda mais para a cronicidade que essa condição detém por natureza.

Os objetivos deste relato são: (a) apontar possíveis critérios diagnósticos para a síndrome de Clérambault; e (b) demonstrar que o tratamento adequado, apesar de resultado incerto, oferece melhor qualidade de vida e prognóstico.

\section{Apresentação do caso}

\section{Identificação}

S., 42 anos, feminino, branca, casada, três filhos ( +919 anos, O' 18 anos, O’ 14 anos), natural de São Bernardo do Campo (SP), procedente de Santo André (SP), desempregada, última ocupação como auxiliar de limpeza, ensino fundamental incompleto, evangélica.

\section{Motivo da consulta}

Encaminhada da unidade básica de saúde com hipótese diagnóstica de "impulso sexual excessivo".

\section{História da moléstia atual}

Há 5 anos, apresenta aumento do "apetite sexual". Diz que "só uma relação sexual por dia não a satisfaz". Dessa forma, costuma manter relações sexuais com o marido até três vezes no mesmo dia. Tem orgasmo em todas as relações. Além disso, masturba-se várias vezes ao dia (até quatro vezes), utilizando-se de instrumentos eróticos. Durante a masturbação, imagina-se com outro homem, especialmente com os cunhados e com o genro. Acredita que muitos homens lhe dirigem olhares lascivos e a desejam sexualmente.

Teve somente um relacionamento amoroso antes do atual matrimônio. Casou-se virgem, aos 23 anos, e teve a primeira filha 1 ano depois.

Após a primeira gestação, na qual perdeu a visão do olho esquerdo por "complicação no trabalho de parto" (descolamento de retina), passou a se interessar por outros homens.

Aos 25 anos, foi orientada pela irmã mais velha a procurar acompanhamento psiquiátrico, porque estava "muito namoradeira". Ficou internada por 2 dias em um hospital psiquiátrico. Após alta, não aderiu ao tratamento ambulatorial.

Aos 35 anos, retomou o tratamento psiquiátrico ambulatorial. No transcorrer das consultas, dizia que seu médico nutria grande interesse sexual por ela: "ele estava apaixonado por mim"; "chegamos a ter uma relação sexual dentro do consultório".

Após 6 meses de tratamento, foi encaminhada para psicoterapia, mas não a fez e parou com a medicação, cujo nome não sabe informar.

Nega abuso sexual e relações homossexuais. Nega alucinações.

$\mathrm{Na}$ primeira entrevista em nosso serviço Ambulatório de Transtornos da Sexualidade das Disciplinas de Psiquiatria e Psicologia Médica da Faculdade de Medicina do ABC (ABSex) -, perguntou ao médico qual era a sua idade e disse que o achava 
muito bonito. Tal comportamento voltou a se repetir em consultas subseqüentes.

\section{Anamnese objetiva (irmã mais velha)}

Após o nascimento da primeira filha, paciente passou a se relacionar com outros homens e dizia que queria se envolver com alguém "que pudesse lhe dar uma vida melhor".

Sua mãe faleceu quando estava com 15 anos, e seu pai casou-se novamente 2 anos depois. O genitor era mais próximo de $\mathrm{S}$. do que dos outros filhos.

Mantinha o discurso de que os homens se apaixonavam facilmente por ela. A irmã estranhou a relação de $\mathrm{S}$. com o psiquiatra anterior, porque ela descrevia os detalhes da vida pessoal do médico e também dizia que ele se declarava apaixonado.

Sempre apresentou dificuldades em arrumar emprego: "ela é limitada". A irmã chegou a contratá-la para trabalhar em sua empresa, mas não foi possível mantê-la no cargo, pela "falta de habilidade e desempenho". Tem contatos sociais pobres e relacionase principalmente com familiares.

\section{Evolução}

Na primeira consulta, introduziu-se risperidona. Permaneceu com tal medicação por apenas 3 semanas, em virtude de "fraqueza e sonolência". Queixou-se também de diminuição do desejo sexual e da freqüência de orgasmos após início da medicação.

Mantinha o discurso delirante de que os cunhados e o genro se interessavam sexualmente por ela. Optouse, assim, pela troca de antipsicótico para haloperidol de depósito (uma ampola a cada 15 dias).

Após a troca de medicação, dizia estar "muito melhor". O delírio erótico se mostrou menos intenso. No entanto, após 2 meses de uso do haloperidol, apresentou sinais e sintomas de liberação extrapiramidal. Foi prescrito, então, biperideno $2 \mathrm{mg}$ via oral.

Quando retornou à consulta, negou-se a dar continuidade ao tratamento com aquele antipsicótico, substituindo-se por trifluoperazina e mantendo-se biperideno oral.

Após 7 dias, suspendeu o uso das medicações por conta própria e apresentava o discurso: "tenho medo de ficar dura de novo".

Mostrava-se paranóide com a equipe médica e com as medicações, olhar parado, afeto embotado. Afirmou diversas vezes que iria abandonar o tratamento: "prefiro ficar do jeito que era antes"; "meu marido também prefere"; "não consigo fazer nada, dura desse jeito".
A família foi convocada pela equipe médica, a fim de se fornecer esclarecimentos da patologia e apoio na aderência ao tratamento ambulatorial.

A paciente permaneceu sem antipsicótico por 15 dias, quando retornaram os pensamentos delirantes de cunho erótico.

Iniciou-se, então, o uso de tioridazina. A dose desse antipsicótico precisou ser aumentada nas 2 semanas posteriores, para $100 \mathrm{mg}$, devido à manutenção do quadro delirante. Paciente mantém uso irregular da medicação, com pobre suporte familiar, apesar das reiteradas advertências da equipe médica. Familiares rejeitam internação.

\section{Antecedentes pessoais}

- É a segunda filha de prole de quatro irmãos.

- Nega uso de álcool, tabaco ou drogas ilícitas.

- É deficiente visual do olho esquerdo ("descolamento de retina").

- Laqueadura há 14 anos.

- Internação psiquiátrica há 18 anos.

- Acompanhamento psiquiátrico irregular há 8 anos.

\section{Antecedentes familiares}

- Pai diabético.

- Mãe hipertensa, falecida aos 35 anos por cardiopatia.

- Duas tias maternas com "problemas psiquiátricos".

\section{Exame psíquico}

\section{Na entrada}

Vígil. Orientada auto e alopsiquicamente. Atenção preservada.

Memória preservada. Pensamento sem alterações formais, contudo caracterizado por idéias delirantes de cunho erótico. Sem sinais indiretos alucinatórios. Eutímica com afeto congruente. Crítica prejudicada.

\section{Atual}

Consciente. Orientada auto e alopsiquicamente. Atenção voluntária diminuída. Pensamento reverberante e lentificado, com latência de respostas e idéias delirantes de cunho persecutório (contra a equipe médica). Sem sinais indiretos alucinatórios. Eutímica, afeto embotado (provavelmente em decorrência do uso do antipsicótico). Sem planos ou ideação suicida. Inteligência prejudicada (não realiza cálculos simples e não abstrai). Juízo da realidade e crítica da morbidez prejudicados. 


\section{Exame físico}

- Sem anormalidades.

\section{Exame neurológico}

- Sem anormalidades.

\section{Exames laboratoriais}

- Não foram identificadas alterações.

\section{Eletroencefalograma}

- Feito em vigília, dentro dos limites da normalidade.

\section{Exame de imagem}

- Ressonância nuclear magnética de crânio mostrando cisternas e sulcos corticais alargados. Moderada dilatação do sistema ventricular supratentorial. Inúmeras lesões acometendo o parênquima encefálico bilateral, predominando junto à substância branca periventricular bilateral, caracterizadas por focos de hipersinal em T2 e DP de caráter inespecífico. Importante deformidade do globo ocular esquerdo, que se apresenta de volume reduzido (Figura 1).

\section{Diagnóstico multiaxial - Diagnostic and Statistical Manual of Mental Disorders - Text Revision (DSM-IV-TR)}

- Eixo I: transtorno delirante, tipo erotomaníaco.

- Eixo II: retardo mental leve.

- Eixo III: deficiência visual de olho esquerdo.

- Eixo IV: problemas econômicos e ocupacionais.

- Eixo V: 65 (AGF).

\section{Discussão}

Trata-se de paciente encaminhada ao ABSex com hipótese diagnóstica de impulso sexual excessivo. No entanto, ela não apresentava a busca pelo sexo em si, mas esperava receber o amor do objeto central de seu delírio. Não foram encontradas alterações de comportamento, como autodestruição, obsessões, fantasias, desistência de atividades sociais, ocupacionais ou recreativas em decorrência da procura por sexo ${ }^{14}$.

Provavelmente, o desconhecimento da síndrome e a má qualidade da anamnese realizada comprometeram $\mathrm{o}$ adequado manejo inicial do quadro. $\mathrm{O}$ inadequado suporte familiar, associado ao prejuízo da crítica da paciente, contribui fortemente para um prognóstico ainda mais indesejável, tendo em vista as reiteradas referências literárias sobre a pobre resposta terapêutica dos
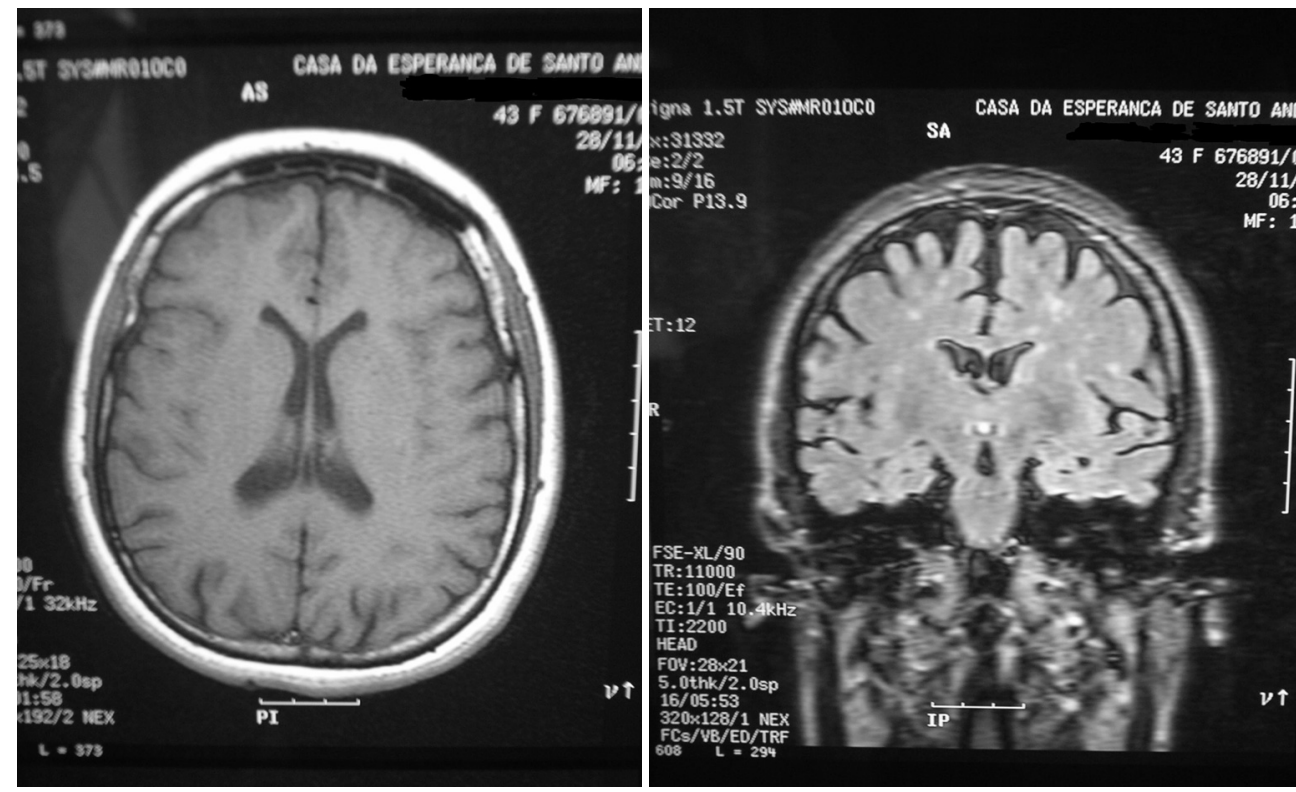

Figura 1 - Ressonância nuclear magnética evidenciando inúmeras lesões que acometem o parênquima encefálico bilateral, de caráter inespecífico. Há moderada dilatação do sistema ventricular supratentorial 
transtornos delirantes crônicos primários às medicações antipsicóticas tradicionais.

Alguns autores apontaram teorias a respeito da etiologia psicodinâmica e orgânica da síndrome de Clérambault. Segal, por exemplo, observou que os pacientes costumam ter algumas características em comum. São pouco atraentes fisicamente, solitários, imaturos, limitados intelectualmente, socialmente inibidos, sexualmente pouco experientes, com empregos de baixo prestígio. $\mathrm{O}$ autor considerou que esses indivíduos procuram atenuar sua inferioridade através de compensações psicológicas, projetando construções delirantes narcísicas em pessoas mais valorizadas socialmente ${ }^{5}$.

Freud já havia proposto que a erotomania seria uma das diversas manifestações do centro de conflito da paranóia e que estaria diretamente ligada a uma relação insatisfatória com a própria mãe. Isso refletiria em dificuldades de relacionamento íntimo, comprometendo, então, a vida conjugal ${ }^{15}$.

Jordan colocou que a erotomania poderia se desenvolver a partir da busca por uma figura paterna segura, erotizada e inatingível, bem como da necessidade do paciente afastar de si impulsos homossexuais ${ }^{16}$.

Como se vê, há múltiplas formas de se apreender psicodinamicamente o fenômeno da síndrome de Clérambault.

Corroborando as características encontradas na literatura, a paciente apresentava preocupação com sua aparência (por diversas vezes perguntou ao entrevistador se estava em bom estado de alinho), demonstrava incômodo com a sua deficiência visual, baixa escolaridade, poucos relacionamentos amorosos antes de se casar, cargos empregatícios sem grande destaque social e dificuldades em desenvolver as atividades designadas. Perdeu a mãe na adolescência e mantinha forte vínculo com a figura paterna.

Tais vivências podem ter trazido conseqüências e influências no funcionamento psíquico de $\mathrm{S}$. Provavelmente, no decorrer das sessões de psicoterapia, essas implicações possam ser clarificadas e, então, relacionadas à etiologia do delírio erótico.

Além dos fatores psicodinâmicos, fatores orgânicos já foram relacionados a essa síndrome.

Testes neurofisiológicos sugeriram que a erotomania poderia estar associada a déficits na flexibilidade cognitiva e na leitura associativa (mediadas pelo sistema frontal subcortical) e a déficits nas habilidades verbal e de visão espacial ${ }^{17}$.

Prejuízos no funcionamento da visão espacial ou lesões no sistema límbico, especialmente nos lobos temporais, em combinação com experiências amorosas ambivalentes e de isolamento afetivo, poderiam contribuir com as interpretações delirantes.
Já déficits na flexibilidade cognitiva poderiam contribuir com a manutenção de crenças delirantes (o conteúdo do delírio, entretanto, seria determinado pela cultura e pelas experiências pessoais de cada paciente $)^{17,18}$.

No relato apresentado, não foram encontradas alterações no eletroencefalograma. Já a ressonância nuclear magnética de crânio apresentou diversas alterações corticais e de substância branca que podem estar envolvidas com o transtorno delirante e desenvolvimento cognitivo limitado. Entretanto, são necessárias novas investigações (inclusive testes sorológicos) para associarmos assertivamente o surgimento da síndrome com o comprometimento cerebral.

Há controvérsias entre diversos autores quanto à classificação da erotomania em primária e secundária. De acordo com o estudo de Gillet et al., é muito difícil considerar um caso como forma pura ${ }^{13}$. Para ser tido como tal, o paciente deve apresentar os seguintes critérios propostos por Ellis \& Melssop ${ }^{11}$ :

- Convicção delirante da comunicação amorosa;

- O objeto de amor é de alto nível socioeconômico;

- O objeto é o primeiro a se apaixonar;

- O início é súbito (dentro de um período de 7 dias);

- O objeto é fixo (ou pode, no máximo, ser substituído por outro);

- Paciente racionaliza o comportamento paradoxal do objeto;

- Curso crônico;

- Ausência de alucinações;

- O delírio deve ser criado sem alteração do nível de consciência.

Segundo esses autores, os pacientes considerados como tendo a forma pura só atingem $80 \%$ desses critérios.

As características da erotomania secundária são?:

- O delírio deve ter origem num transtorno mental de base (podendo aparecer

antes, durante ou após esse transtorno);

- As características clínicas do distúrbio psiquiátrico primário estão presentes, além do delírio erótico;

- A erotomania se resolve quando a doença de base é tratada.

Os transtornos mais associados ao delírio erótico são: esquizofrenia (34\%), síndrome depressiva (13\%), transtorno afetivo bipolar (9\%) e paranóia (9\%).

De Clérambault considerou que a erotomania poderia ser uma síndrome clínica transitória e sobreposta a transtornos paranóides, bem como um dos pródromos da esquizofrenia, ou mesmo uma entidade clínica autônoma ${ }^{4}$.

Observa-se que a paciente apresentou critérios suficientes da síndrome pura. Em contrapartida, na 
literatura, não foram encontradas referências da associação entre alterações morfológicas cerebrais e a síndrome.

É comum serem encontrados traços de personalidade pré-mórbida, especialmente na erotomania pura. Estes são indivíduos descritos como tímidos, delicados, sensíveis, desconfiados, pouco sociáveis. No estudo de Mullen \& Pathé, a personalidade anti-social é a que predomina, seguida das personalidades esquiva, narcísica e paranóide9.

Quando traços pré-mórbidos de personalidade antisocial estão presentes, é comum que o paciente apresente comportamento promíscuo e violento, além de fantasias sexuais parafílicas (principalmente necrofilia, voyeurismo e sadismo $)^{9,19}$.

De acordo com Goldstein, há potencial risco de comportamento violento pelo paciente erotomaníaco. Em sua amostra forense, $57 \%$ dos pacientes se envolveram em situações violentas (ameaça, perseguição, estupro, homicídio). Na sua maioria, eram do sexo masculino e muitos associados ao diagnóstico primário de esquizofrenia e transtorno de personalidade ${ }^{19}$.

Quando a amostra provém de presídios ou unidades de reabilitação, a incidência entre homens supera a feminina. Já na população geral, os homens somam somente 20 a $30 \%$ dos casos de erotomania ${ }^{20}$.

Normalmente, a agressividade decorre das seguidas rejeições sofridas pelo paciente por seu objeto de amor.

Na história de S., não apareceram comportamentos violentos. No entanto, é possível que ela tenha investigado dados pessoais da vida de seu psiquiatra anterior, já que, segundo a irmã, ela sabia de muitos detalhes da intimidade de seu objeto.

Baseado nos critérios do DSM-IV-TR (American Psychiatric Association ${ }^{21}$, a paciente foi diagnosticada como portadora de um transtorno delirante, porquanto os delírios não são bizarros, com duração de mais de 1 mês, e também não apresentou critérios que satisfizessem outras patologias como esquizofrenia, transtorno afetivo bipolar, síndrome depressiva e uso de substâncias psicoativas. De acordo com o tema central do seu delírio, foi considerado dentro do subtipo erotomaníaco ${ }^{14}$.

A síndrome de Clérambault é uma doença crônica, considerada relativamente refratária ao tratamento, tanto farmacológico quanto psicoterápico ${ }^{2}$.

É postulado direcionar o manejo clínico para esmorecer o delírio, a fim de diminuir o nível de estresse a que ficam submetidos tanto o paciente quanto o objeto de amor?.

Esses pacientes trazem drama à vida da vítima e transtornos psicológicos e sociais em conseqüência da impiedosa perseguição, que pode durar anos.
Com relação ao tratamento, os antipsicóticos típicos são os mais utilizados, embora seus efeitos sejam considerados modestos, com pouca ação sobre o núcleo delirante (autores citam a pimozida como droga alternativa, especialmente naqueles casos onde há a associação de delírios erótico-paranóides com alucinações sexuais somáticas). Somente a minoria alcança completa remissão de seus sintomas.

Atualmente, os antipsicóticos atípicos são preconizados, em especial a risperidona, em doses menores que $6 \mathrm{mg}$ ao dia. Há relatos de rápida resolução dos delírios eróticos quando se associa a hospitalização ${ }^{1,9,12}$.

Ocasionalmente, a eletroconvulsoterapia pode ser bem indicada, mas também têm sido relatados resultados frustros ${ }^{2,9}$.

Não há evidências de que psicoterapia ajude esses pacientes, especialmente se for a única forma de tratamento.

Alguns indivíduos, quando separados de seus objetos amorosos (problemas judiciais, hospitalizações), podem apresentar melhora do delírio, principalmente se tratados adequadamente ${ }^{5}$.

\section{Conclusão}

Em razão da escassa literatura sobre o assunto, pouco se pode afirmar sobre a etiologia desses casos. Teorias psicodinâmicas e alguns achados orgânicos têm sido apontados, mas de forma isolada. Achados neurobiológicos poderão contribuir para maiores esclarecimentos dessa síndrome.

Um bom entendimento da psicopatologia da erotomania pode aumentar o reconhecimento dessa síndrome e proporcionar o melhor tratamento, oferecendo alívio ao paciente e aos familiares, além de diminuírem as possibilidades de comportamento agressivo e violento direcionado ao objeto de amor.

\section{Referências}

1. Kelly BD, Kennedy N, Shanley D. Delusion and desire: erotomania revisited. Acta Psychiatr Scand. 2000;102(1):74-5.

2. Calil LC, Terra JR. Síndrome de De Clerambault: uma revisão bibliográfica. Rev Psiquiatr RS. 2005;27(2):152-6.

3. Kraepelin E. Maniac-depressive insanity and paranoia. Edinburgh: E \& S Livingstone; 1921.

4. De Clérambault GG.(1042). Les psychoses passionnelles. In: De Clérambault GG. Oevres psychiatriques. Paris: Presses Universitaires; 1942. p. 315-22.

5. Segal JH. Erotomania revisited: from Kraepelin to DSM-III-R. Am J Psychiatry. 1989;146(10):1261-6.

6. Raskin DE, Sullivan KE. Erotomania. Am J Psychiatry. 1974;131(9):1033-5.

7. Rudden M, Sweeney J, Frances A. Diagnosis and clinical course of erotomania and other delusional patients. Am J Psychiatry. 1990;147(5):625-8. 
8. Phillips MR, West CL, Wang R. Erotomanic symptoms in 42 Chinese schizophrenic patients. Br J Psychiatry. 1996;169(4):5018 .

9. Mullen PE, Pathé M. The pathological extensions of love. Br J Psychiatry. 1994;165(5):614-23.

10. Berry J, Haden P. Psychose passionnelle in successive generations. Br J Psychiatry. 1980;137:574-5.

11. Ellis P, Mellsop G. De Clerambault's syndrome: a nosological entity? Br J Psychiatry. 1985;146:90-5.

12. Calil LC, Terra JR. Síndrome de De Clerambault: segundo relato de caso em português. Rev Psiquiatr RS. 2005;27(1):64-9.

13. Gillet T, Eminson SR, Hassanyeh F. Primary and secondary erotomania: clinical characteristics and follow-up. Acta Psychiatr Scand. 1990;82(1):65-9.

14. Goodman A. Sexual addiction: nosology, diagnosis, etiology and treatment. In: Lowinson JH, Ruyz P, editors. Substance abuse: a comprehensive textbook. 4th ed. Philadelphia: Lippincott Williams \& Wilkins; 2005. p. 504-39.

15. Freud S. On mechanism of paranoia. In: Rieff P. The collected papers of Sigmund Freud. New York: Collier; 1911. p. 29-48.

16. Jordan HW, Howe G. De Clerambault's syndrome (erotomania): a review and case presentation. J Natl Med Assoc. 1980;72(10):97985.

17. Fujii DE, Ahmed I, Takeshita J. Neuropsychologic implications in erotomania: two case studies. Neuropsychiatry Neuropsychol Behav Neurol. 1999;12(2):110-6.

18. McGuire BE, Akuffo E, Choon GL. Somatic sexual hallucinations and erotomanic delusions in a mentally handicapped woman. J Intellect Disabil Res. 1994;38(Pt 1):79-83.

19. Goldstein RL, Laskin AM. De Clerambault's Syndrome (Erotomania) and claims of psychiatric malpractice. J Forensic Sci. 2002;47(4):852-5.

20. Menzies RP, Federoff JP, Green CM, Isaacson K. Prediction of dangerous behavior in male erotomania. Br J Psychiatric. 1995;166(4):529-36.

21. American Psychiatric Association (APA). Manual diagnóstico e estatístico de transtornos mentais (DSM-IV-TR). $4^{\mathrm{a}}$ ed. Porto Alegre: Artmed; 2003. 